\title{
Challenges of Digital Learning Faced by College English Teachers in China
}

\author{
Yu lei \\ Department of Foreign Languages, Shenyang Aerospace \\ University \\ Shenyang, China \\ E-mail:yuleicathy@126.com
}

\author{
Qi Zhenguo* \\ School of Educational Technology, Shenyang Normal \\ University \\ Shenyang, China \\ E-mail:qizhenguo@126.com
}

\begin{abstract}
The digitization of education is an inevitable trend of education development in our country and an important part of the teaching reform of education in colleges and universities. The application of information technology changes the traditional teaching model. College English teachers should adapt to the development of educational digitization and rise to the occasion brought about by digital learning. This article obtains relevant information through questionnaires, interviews and other methods and analyzes the data obtained. It then summarizes the opinions and attitudes of college English teachers on E-learning and analyzes the challenges in teaching design, challenges in teachers' technical ability in Education, challenges in changing roles and challenges in time distribution management, etc. It also put forward relevant strategies and suggestions for foreign language teachers in colleges and universities. The study of this paper is of great significance to the promotion of college English teaching reform in the digital environment.
\end{abstract}

Keywords-Digital learning; Instructional design; Teaching interaction; Blended learning

\section{AN OVERVIEW OF DIGITAL LEARNING}

\section{A. The concept of digital learning}

The concept of digital learning comes from the definition of foreign scholars, mainly referring to Electronic Learning or Digital Learning, which is also translated as E-learning. In 1998, an American scholar Jay Cross first proposed the term "E-Learning". The "white paper on education technology in 2000" from the American Ministry of education pointed out that "E-Learning" is a form of education, including the new communication mechanism and the interaction between people. These new communication mechanisms are: computer network, multimedia, professional content website, information search, electronic library, distance learning and online classroom. The broad sense of digital learning refers to the learning behavior of using electronic technology and media, including TV broadcast, traditional video, audio and CD-ROM and the Internet. The narrow sense of digital learning refers exclusively to Internet-based learning.

\section{B. The characteristics of digital learning}

Digital learning is open which breaks through the closure of traditional teaching and realizes learning every time and every where. Digital learning is interactive, which inherits the interactivity of traditional teaching (face-face), but there is a great difference from the traditional teaching. The interaction of digital learning is conducted online, and it can be synchronous or asynchronous. Digital learning is collaborative, providing teachers and learners with the platform of digital learning and the environment of collaboration and communication, through which can achieve collaborative learning. Digital learning is traceable, and all learning activities of learners are recorded as a basis for assessing learning effectiveness and analyzing learning needs. Digital learning is authentic. Although learners are learning in a virtual environment, the learning situation is real. Digital learning is technical, and the realization of digital learning is closely related to technology, including information technology, network technology and related hardware and software technology [1].

\section{RESEARCH BACKGROUND AND PROCESS}

The informatization of education is the inevitable stage of education development in our country and the important part of the teaching reform of education in colleges and universities. Up to now, $100 \%$ universities in our country have built the campus network, and $100 \%$ of the colleges and universities have built or purchased the network teaching platform, and the network teaching is being or will be carried out, and the reform of the teaching mode is in depth. As a part of it, college English teaching is naturally to adapt to the requirements of teaching reform.

The object of this paper is the public English teachers in colleges and universities, and English teaching refers to the public English teaching. In order to fully understand the application of digital learning in college English teaching and what challenges it brings to English teachers, this paper makes an in-depth study through the methods of investigation, interview and field observation. 160 English teachers from four universities filled out the questionnaire, and conducted surveys combined field and network, whose professional titles range from professors to teaching assistants, whose degrees 
from doctorates to bachelors. Most teachers accept the new teaching mode reform and the digital teaching. It is believed that digital learning mode is a good teaching mode, which will promote college English teaching and improve the quality of college English teaching. But adapting to digital learning requires a process, and digital learning will pose challenges.

\section{RESEARCH DISCOVERY}

\section{A. Challenges in teaching design}

About 30 percent of teachers feel that under the background of digital learning, the ideas of new instructional design will challenge themselves in the context of digital learning, and new teaching design needs to be learned in the face of digital learning. About 36 percent of teachers believe they can solve the challenges they have faced in a short period of time without affecting their teaching. About 18 percent of teachers believe that digital learning poses no challenge to them and is willing to accept new teaching models. The challenges in instructional design are mainly reflected in the major changes in teaching methods, the flexibility and diversity of teaching interactions, and the computerization of teaching resources. Students' learning environment has also changed, and the Internet has become the carrier of teaching and learning.

From the results of the survey, about 50 percent of the teachers are used to the face-to-face (face - face) teaching, insisting that face-to-face teaching is the best teaching method, and there is no systematical study and try on the reform of digital learning mode.

In the process of interview, investigation and discussion, it is found that teaching interaction has become a key concern of English teachers, which is posing a challenge for some teachers. The public English teaching focuses on listening, speaking, reading, writing and translating. At present, the public English teaching in most of our country can not achieve true small-class teaching. The large-number students in class has created problems in the traditional face-to-face (face-face) teaching mode. The interactive forms of digital learning mode are e-mail, discussion post, chat room, group, blog, fetion, online community and so on. The interaction has synchronous and asynchronous modes [2]. The interaction between students and teachers has become diverse. Teachers pay attention to e-mail, discussion posts, chat rooms, groups, blogs, fetion, online communities, etc., and they often reflect that it is difficult to communicate with students and get feedback in time. Synchronization form can be achieved only when teachers and students are one to one or to a few students. In most cases, asynchronous form is used. Teachers' online interaction-correcting homework, answering e-mail and participating in discussion will occupy a lot of time of them. Although the technology can meet the needs of students who want to see the teacher's expression and hear the teacher's voice, some teachers still feel uncomfortable. Most of the teachers require the students to complete the interaction through the online teaching platform and give full play to the management function of the platform, so as to improve the efficiency of the interaction.
At present, the public English teaching in our universities is facing the pressure that students have to pass CET4 and CET6. Some schools have taken the students' passing rate of CET4 and CET6 as an assessment indicator for English teachers, which makes them worry about changing the teaching mode. Through investigation, we know that teachers are more interested in some English learning websites, and actively recommend their students to participate in interviews. In particular, access to some English websites helps to improve students' reading ability.

Most English teachers in ordinary universities have concerns about the evaluation of students based on the digital learning model. Some English teachers in the key colleges and universities approve the online evaluation, the level of which is significantly higher than that of the normal universities teachers. The teachers who are worried about online evaluation believe that online testing and evaluation can not accurately reflect the students' learning effect as students may use computer technology to paste and copy the answers. It is also difficult to evaluate students' learning effects by requiring each student to participate in the discussion of online problems or to respond to a certain number of discussion posts. It is not scientific to evaluate the students' learning effects on the frequency of participating in the discussion on the Internet. The unfairness of online assessment results in students' dissatisfaction with the evaluation mechanism, and the reliability of online evaluation is questioned.

\section{B. Challenges of teachers' technical ability in Education}

The implementation of digital learning based on college English teaching needs the support of relevant technology, mainly embodied in the technology related to computer and Internet. The operation of the computer, the use of computer software, the network communication, the conventional teaching media, the application of the network teaching platform and so on directly affect the development of digital learning. If teachers do not have these knowledge and skills, it will be difficult to carry out digital learning [3].

Through questionnaires and interviews, it is found that about $35 \%$ of the teachers lack the necessary computer technology. Some teachers feel that the application of network teaching platform is more complex, and some complex electronic content needs special software, hardware and high-speed network. Complex network teaching systems and electronic content make them nervous or even afraid. The unscheduled system updates and data processing of the teaching platform management department (Modern Educational Technology Center or other offices) cause some teachers to worry that the data or teaching content stored in the teaching platform system will be lost, and the stability of the teaching platform system and the network will also bring anxiety to the teachers, as a system maintenance will directly affect the teacher in class. Teachers are worried about the reliability of the network teaching platform, and the frequent updates of the operating system and application software give them a lot of pressure, especially they may feel embarrassed and helpless when the system problems have arisen in the process of using the network teaching platform for classes. So they need to prepare two sets of scheme for the lesson in case some problems of the network teaching platform do not affect 
teaching, which will bring the burden on the workload of the teachers.

Teachers in the language laboratory or multimedia classroom reflect that some equipment is managed by the school, and needs being reserved in advance, and needs being taken to the classroom before lessen, which are inconvenient for them to prepare the course. Some courses require teachers to arrive at the class site ahead of a long time to coordinate the use and debugging of related equipment, which can make some teachers tired of.

\section{Challenges of changing roles}

About $27 \%$ of teachers believe that the changing roles pose a challenge to teachers, which can be summarized as following aspects: teachers are changed from knowledge speakers, resources providers into domain consultants, learning guides, resource inquiries; the development of network technology and the rapid expansion of information have made teachers and students have equal rights in resources possession, and the authority of teachers to possess resources is challenged. Teachers need to learn how to help students quickly inquire and select meaningful information resources [4] (Zhong Zhixian, 2006). from the problem speakers into the problem participants, and teachers create the discussion situation for students under the network environment, and stimulate students the enthusiasm of raising questions and discussing problems. Teachers' roles have changed from the author of the learning content into the designer and the monitor of the learning practice, and teachers create the situation for the students' learning construction, provide the logical relationship and learning method for the students, and grasp how to support, guide and monitor in the learning process. Teachers' roles have changed from the state of absolute autonomy into a wide range of evaluation, not only the conventional evaluation, but also other aspects of evaluation, such as teachers' information literacy and cooperation, etc. The unified teaching mode for students should be in accordance with the aptitude and the characteristics of different students. Students' academic viewpoint of a single theory should be stimulated into a variety of views on the same topic. Teachers' roles have changed from the teaching rulers into the participants in the learning process, and from a teacher into a learner, which have put forward new requirements for the professional development and knowledge expansion for teachers [5].

\section{Challenges of time distribution management}

How to allocate and manage the time of College English teaching based on digital learning model has brought challenges to English teachers. After 1997, the scale of college enrolment has expanded and the number of students is increasing rapidly. As a public course in colleges and universities in China, college English teachers usually have a large amount of class hours, basically at 12 hours / weeks. Above, some schools even reach 18-20 hours / weeks, so teachers' time after class is relatively less than that of other professional teachers, and the curriculum design based on digital learning will take more time for teachers. After class, teachers should spend a lot of time collecting data suitable for digital learning and convert text materials into electronic materials. These work will take up a large number of teachers' after-school time. At the same time, teachers also provide online help and guidance for students and are faced with a large number of students in multiple classes to discuss online, which is impossible for teachers to complete. While learning the course content, they will spend a lot of time learning how to use the tools needed in digital learning. An interesting phenomenon was found in the survey that students who were reluctant to interact with teachers in the classroom would be more willing to interact with teachers on the Internet, so the students' time did not change too much, and the time taken by teachers to adapt to digital learning would be significantly increased.

Teachers are confronted with time management problems in providing teaching resources. There is also a problem of time efficiency in digital courses. Usually, teachers should put the video and related resources on the Internet for the students to review, which needs a fixed time. Many teachers don't know that they will take up a lot of time at the beginning of the course, but with the deepening of the course, teachers feel that time is getting more and more intense.

\section{E. Other challenges}

A few English teachers have psychological barriers because of their appearance in the digital learning, especially some female teachers feel that their video image is not beautiful and beautiful, and they do not want to put the lecture video on the Internet. Some teachers do not face the camera naturally, which affects the effect of teaching. Some teachers' pronunciation is not standard, which is not obvious in the face-face class, but it is very embarrassing when the video is broadcast.

The data show that copyright is a relatively concerned issue for teachers. If it can not be properly solved, it will affect the sharing of some teachers' teaching resources. The protection of personal privacy and copyright is a problem that has to be taken into consideration in the digital learning model. Some teachers are worried about the use of plagiarism on the Internet, and some teachers worry about the use of other people's teaching resources to violate the copyright of others.

The policy support for the reform of the digital mode of English teaching will also affect the college English teachers. Many universities have no difference in the requirements of tasks outside the teaching for public English teachers and other professional curriculum teachers, and they must complete the corresponding scientific research tasks, which makes college English teachers are not willing to put their energy into the digital teaching model. Some English teachers who spend a lot of energy and time in digital learning feel unbalanced and feel that their work can not be recognized by the school administrators.

\section{REFLECTION AND SUGGESTION}

The challenges of digital learning model for college English teachers are mainly reflected in the transformation of teaching design ideas, the improvement of teaching methods, the change of teaching environment, the interaction of teaching online, the diversification of teaching evaluation, the transition of teachers' role, and the promotion of teachers' educational skills, etc. [6] 


\section{Distribution of challenges in digital learning}

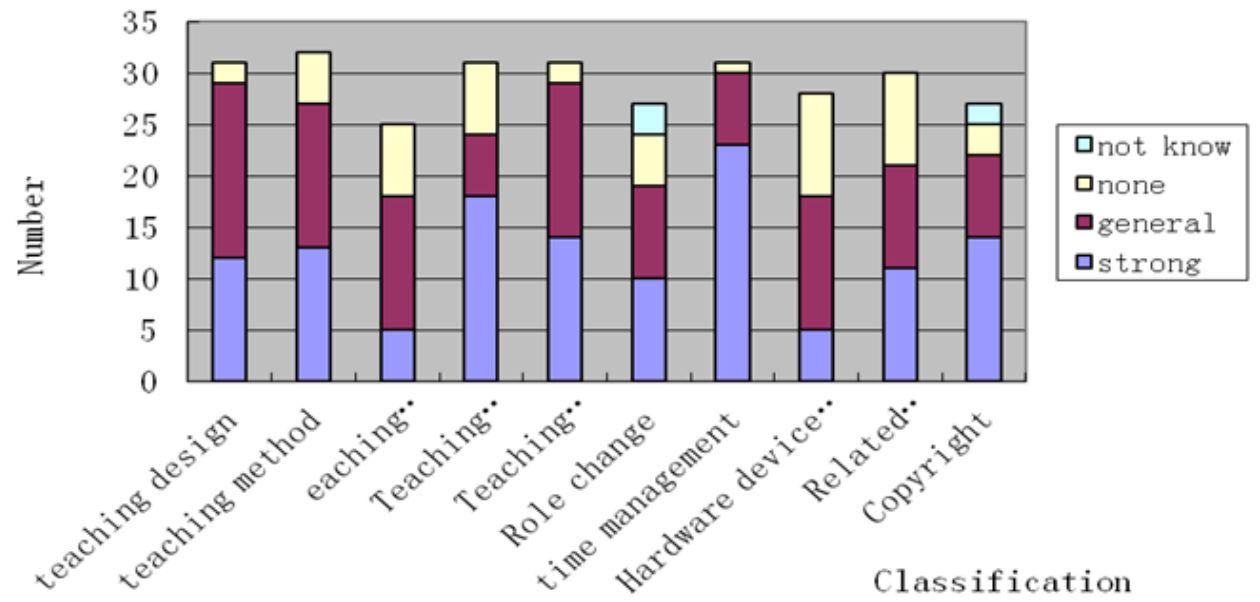

Fig. 1 The distribution of challenges in digital learning

The digital learning of college English is a systematic project, which involves all aspects of teaching, including human resources construction, equipment technology foundation, capital, management, service, etc. Therefore, it is necessary for the decision-making department of the school, the management department, the usage unit and the participants to work together to achieve it [7].

Blended Learning is the best teaching model, and digital learning can not replace the traditional teaching mode. [10] It can transfer the appropriate content to the appropriate learners at the appropriate time in the appropriate way, so as to maximize the knowledge migration.

The policy support and cooperation of the school management department will promote the reform of the digital learning model. The school should revise the evaluation mechanism for teachers, encourage teachers to carry out the teaching of digital learning mode and appropriately reduce the workload of teachers who carry out the reform of digital learning mode and the requirements of scientific research assessment of college English teachers.

Regularly carry out the educational technical ability training for teachers, including teaching design, interactive teaching, teaching evaluation method, application of network teaching system, and training of software and hardware in common use; carry out the teaching seminars and exchange meetings or other activities of digital learning mode to increase communication among teachers; Write the system's digital learning application manual and make video materials, establish professional technical service team and complete service system; make known the details how to carry out the technical methods of copyright protection, let the teacher lay down the burden without psychological barrier, and formulate the protection of copyright.

\section{REFERENCES}

[1] Zhang Jianwei, Sun Yanqing, et al. Design and evaluation of e-learning [M]. Beijing: Beijing Normal University press, 2006.

[2] Wen Yingqian. College English teaching mode under the network environment $[\mathrm{J}]$. Journal of Guangxi Institute of Education, 2008(4):57-58.

[3] Su-Chen WANG, Bronwen COWIE, Alister JONES. Challenges of e-Learning for University Instructors in Taiwan [C]. The 16th International Conference on Computers in Education. TaiPei: 2008.229-237.

[4] Zhong Zhixian. Information based teaching mode [M]. Beijing: Beijing Normal University press, 2006.

[5] Qi Zhenguo, Wang Qiong. E-learning's challenge to China's University Teachers: [J]. audio-visual education research,2009(7):21-25

[6] YairLevy. Assessing the Value of E-Learning Systems [M]. USA: Information Science Publishing, 2005.

[7] Adam D. Fein, Mia C. Logan. Preparing Instructors for Online Instruction $[\mathrm{J}]$. NEW DIRECTIONS FOR ADULT AND CONTINUING EDUCATION, Wiley Periodicals. Inc, No.100.2003:45-48. 